\title{
Localization of Activity in the Brain
}

$I^{N}$ $\mathrm{N}$ his Ferrier Lecture to the Royal Society, Prof. E. D. Adrian (Proc. Roy. Soc., B, 126, 433 ; 1939) traces the development of the electro-physiological methods of investigation and analysis of the activities of the cerebral cortex from the discovery of the electrical excitability of the brain by Fritsch and Hitzig in 1870. This discovery led to Ferrier's classical work on cerebral localization, the main facts of which have never been seriously questioned, and, indirectly, to the modern method of study of cerebral function, the recording and analysis of the waves of electrical potential, which are the inevitable accompaniment of cortical activity.

Berger's observation that the electrical activity of the cortex could be detected through the unopened skull came at a time when the range of electrical technique was increasing enormously, and the result has been a great and sudden increase in the volume of work published on the subject. The great beauty of the method is that it allows a study of the activity of the whole cortex, and not merely in "the arrival and departure platforms"; but it has the inevitable difficulty of the interpretation of the records from an organ which, by its very nature, never responds twice in precisely the same way. Thus, the local electrical response, which has been shown to follow the arrival of sensory impulses, is related in size, not to the stimulus, but to the previous history of the cortical area on which it falls. In fact, the mechanism of the various types of facilitation which are in constant evidence in the cortex is one of the most fascinating problems.

Some details of the spread of activity in the cortex can be studied in the response of the sleeping, or narcotized, brain to the arrival of a sensory message, but a simpler, because more easily controlled, method is the investigation of the response of the cortex to a direct electrical stimulus. Such a stimulus evokes a reaction locally, not unlike that in response to a sensory message. In the surrounding areas it has two distinct effects : the direct spread of the excited state and a diffuse general increase in excitability, which reveals itself, after repeated stimulation, in the wide spreading of waves of considerable electrical potential, very like those which occur in man during epileptiform convulsions.

It is evident that the cerebral cortex responds readily to sensory messages, and it is therefore difficult to define what is meant by the 'spontaneous' activity of the brain. It seems clear, however, that although the response is to some degree controlled by the character and size of the message reaching it, the final pattern of the cortical activity is determined by the structure of the particular region and by its history. However hopeless may seem the task of analysing the activity of the human brain, these new methods offer some hope, at least, of understanding the mechanisms which exist in it, and from which its behaviour is eventually synthesized.

\section{The Spens Report and General Science}

\section{Discussion by the Association of Women Science Teachers}

$\mathrm{T}$ HE Association of Women Science Teachers held an extraordinary general meeting on March 4 at St. Paul's Girls' School, by kind permission of the Governors and the High Mistress, to consider : (1) the Spens Report in its relation to science in the curriculum; and (2) the Report on General Science, Part 2, recently published by the Science Masters' Association.

The Spens Report sees the value of "the natural sciences when vitally taught" and it emphasizes the need for general interest, but it indicates that this might require less time than a formal study. The idea that the wider study of science might require less time was questioned by the meeting, but members were in agreement that there is still room for pruning and taking stock of the topics which are included, so that the science teaching might instil the desire "to search for truth, goodness and beauty" and give some understanding of the part played in the modern world by the forces of science. Some felt that the emphasis on English subjects as the core of the curriculum might subordinate science, but all were agreed that all subjects had an important part to play in the teaching of English.

There was considerable variation in opinion as to the time which should be allowed to science, but it was felt that the time suggested by the Spens Report is adequate for a general view, but where greater detail and depth of knowledge are desired, more time is necessary. There are, however, the 'pool periods' for which science specialists can make a claim. There was general agreement that specialization at an early age is not desirable. It was felt by many that the school child of to-day is over-taught, and that there is a definite need for leisure in school time so that there might be an opportunity for reading; for this to be of real value the school must possess a good library.

The Spens Report also emphasizes the need for good demonstrations as against excessive practical work on the part of the pupil. There was general agreement that, to produce such demonstrations, both time and good laboratory assistants are essential ; it was also felt that demonstrations might be overdone at the expense of the pupil, who obtains satisfaction from the activity involved in practical work. Care is required to keep the balance between demonstration and individual work by the pupils.

The general feeling of the meeting on the Spens Report can be summed up in the words of a member, who said: "Here we have the core of something which is going to give the mass of our child population 